\title{
Dissensões sobre o Público e o Privado na República Islâmica do Irã
}

Youssef Alvarenga Cherem Dentre os países islâmicos, o Irã é um caso peculiar. Definindo seu estado como uma

UNICAMP República Islâmica baseada na doutrina xiita, suas instituições políticas e a construção do estado durante e após a Revolução Islâmica de 1979 são carregadas de uma ambigüidade derivada da tentativa de conceber um estado moderno, democrático, e ao mesmo tempo fundamentado em preceitos religiosos. É por este fato, entre outros, que o Irã representa um ótimo estudo de caso para uma análise das dinâmicas das representações sociais do islamismo político, dentro do panorama geral das relações entre cultura e política e, mais especificamente, das relações entre as representações coletivas sobre a moralidade política (a prática da política) e sua expressão institucional. Percebe-se de fato, naquele país, uma incongruência com a situação de outros países da região, e também em relação à ideologia islâmico-política de transposição ou fusão (de fato e de direito) entre religião e política. Essa incongruência resulta, por paradoxal que possa parecer, do próprio fato de se haver estabelecido um estado islâmico no Irã, e se expressa numa situação específica: a um estado que quer organizar toda a vida política, social e familiar em termos islâmicos, contrapõe-se uma sociedade que, mesmo em seus grupos mais religiosos, e mesmo nos setores considerados mais "tradicionais" (os camponeses), é reticente à organização estatal do fato religioso e da vida familiar. ${ }^{1}$

As recentes manifestações estudantis contra a repressão estatal, em 1999 e 2003 , bem como a resposta das autoridades das instituições estatais ou para-estatais, inscrevem-se numa tradição de confronto entre a sociedade e o estado que data desde finais do século dezenove. Esse tipo de padrão de relações entre o estado e a sociedade pode ser caracterizado propriamente de moderno, na medida em que se diferencia do padrão anterior de separação fundamental entre o estado e a comunidade, e se inscreve num padrão de progressiva construção nacional durante todo o século vinte. Tais eventos nos conduzem também a reconsiderar algumas categorias comumente empregadas na análise de eventos sociopolíticos no Oriente Médio - ou melhor, nos levam a reavaliar o emprego dessas categorias. ${ }^{2}$ 
Meu argumento principal é que o contexto do movimento "reformista" do presidente Khatami nos anos 90 pode ser mais bem compreendido através do prisma da ordenação da vida social pela oposição das categorias público e privado. Os conflitos políticos que se configuram a partir do fim da década de 90 são resultados de uma fissura entre setores do estado e grupos sociais sobre a constituição e organização dessas duas esferas. Conseqüentemente, o conceito de legitimidade - embora freqüentemente relegado ao papel secundário de epifenômeno na configuração do poder político - permeia essa dialética estado-sociedade, e é imprescindível para se compreender as mudanças normativas profundas que se anunciam como uma possibilidade dentro do conjunto de interesses que se formam num momento de estabilização e normalização de um sistema político que, até os finais da década de 80, era pautado pela lógica de dois fenômenos políticos e sociais desestabilizadores, e muitas vezes concomitantes: a revolução e a guerra.

Esse momento é caracterizado pela estabilização e pelo aprofundamento dos resultados da construção revolucionária duma República Islâmica no Irã. Houve uma progressiva normalização dos processos políticos (com a reestruturação do serviço público e a criação de um novo corpo de funcionários, juntamente com a prática recorrente de eleições, o que possibilita uma certa mudança política sem grandes atritos), mas, devido a sua estrutura política ambígua e policêntrica, o sistema ainda é suscetível a tensões tanto entre as próprias instituições políticas quanto em sua interface com a sociedade. Assim, se por um lado assistimos a uma tendência constante de racionalização, burocratização e especialização da máquina de estado, por outro lado percebe-se a subsistência de instituições que escapam a um controle normativo estrito e cujas atribuições são arbitrárias e pessoais. De forma que é muito tênue a linha que separa interesses de grupos sociais do assim chamado interesse nacional ou, em outros termos, aquilo que separa interesses particulares do interesse da sociedade iraniana, e é aí que recai a clivagem público-privado, constituindo-se em uma zona contenciosa à qual se incorporam questões específicas.

Vários autores têm apontado para essas características de racionalização e burocratização a partir do fim da guerra com o Iraque, distinguindo um momento pós-revolucionário em que a dedicação ao regime não seria mais medida em termos de pureza ideológica e militância em organizações políticas ou no engajamento político nas ações empreendidas ou controladas pelo estado. Com o fim de uma guerra de oito anos e com imensas perdas humanas e materiais (centenas de milhares de mortos e feridos), percebe-se a necessidade de reconstrução física e econômica do país, e, para tanto, havia mais necessidade de quadros técnicos especializados do que de militantes ideológicos devotados ao sistema.

A normalização e racionalização da política vêm acompanhadas pela importante mudança institucional caracterizada pela formalização do Conselho de Discernimento do Interesse do Regime Islâmico e pela reformulação do cargo de Guia da Revolução, assegurando uma passagem quase imediata do poder, após a morte de Khomeini, para Ali Khamenei, antigo presidente da república, enquanto que Hashemi Rafsandjani, presidente do parlamento, tornou-se presidente da república. O Conselho do Discernimento do Interesse foi criado em 1988 por Khomeini para arbitrar as questões pendentes entre o parlamento e o Conselho dos Guardiões, que deveria velar pela 
islamicidade das leis, e que recusava sistematicamente as leis parlamentares. A criação desse Conselho pôs fim ao impasse que geravam as novas situações que surgiam para o direito canônico, que até então na história xiita não se via na necessidade de se debruçar diretamente sobre negócios de governo. A solução final encontrada é a dogmatização de uma teoria de estado xiita (a teoria khomeinista do velayate faqih). Em outras palavras, para se fazer um estado religioso, teve-se que estatizar e centralizar a religião, às vezes de uma maneira que não é nada menos que revolucionária: Khomeini afirmou que o mandato absoluto do jurisconsulto é "o mais importante dos mandamentos divinos e tem prioridade sobre todos os mandamentos divinos derivados (...) Trata-se de um dos mandamentos primários do islã e tem prioridade sobre todos os mandamentos derivados, mesmo sobre a oração, o jejum e a peregrinação a Meca"33 (citado em Arjomand 1993: 96).

Essa declaração de Khomeini pode, portanto, ser considerada um marco da separação entre a política e a religião no Irã, e, juntamente com a reforma constitucional que se seguiu, representa a supremacia da razão de Estado sobre a tradição religiosa. O Estado, ao tentar estabelecer seu domínio no discurso religioso, muda radicalmente a natureza da religião.

No mesmo ano (1988), Khomeini ordenou a criação de uma comissão para revisão da Constituição. ${ }^{4} \mathrm{O}$ comitê teve dois meses para apresentar um projeto de revisão constitucional em relação aos seguintes pontos, entre outros: 1. os atributos do Líder; 2. fortalecimento do executivo; 3. centralização do judiciário; 4. centralização da administração de rádio e televisão; 5. institucionalização da Comissão para a Determinação do Interesse. Khomeini sugeriu substituir a exigência de que o Guia fosse uma fonte de imitação - segundo ele, um "jurista justo" aprovado pela Assembléia dos Expertos seria suficiente. Em outras palavras, o Guia teria que ter "vocação política", e não o conhecimento acadêmico religioso, e reconhecer a preponderância religiosa desse homem político seria uma obrigação religiosa, segundo as palavras do então presidente, Khamenei, que depois se tornaria Guia. ${ }^{5}$

Uma das conseqüências dessas mudanças constitucionais foi a estabilização do processo político iraniano, mas a ascensão de Khamenei ao poder cria outros inconvenientes, já que ele é um simples hodjatoles/am, ou seja, está abaixo da categoria de ayatollah na hierarquia clerical xiita, e portanto mais suscetível a críticas políticas, principalmente de grandes autoridades religiosas.

Esse processo de criação de instituições e de certa normalização dos procedimentos políticos dentro do estado tem dois problemas principais, que são fontes de conflitos dentro da elite política e entre essa elite e a sociedade. O primeiro conjunto de problemas é a fragilidade do sistema que surge de sua própria configuração institucional e legal; o segundo grupo de problemas surge da dissociação entre o estado e a sociedade no Irã.

O processo de tomada de decisões políticas no Irã não é claro ou formalizado, ele não é explicitado nem no espírito nem na letra da lei. Ele precisa no mínimo, digamos, de uma boa dose de boa-vontade e concórdia política, para não dizer um consenso mudo, entre as instituições que têm o que se pode caracterizar como um "domínio conjunto" sobre elementos-chave do processo. Isso acontece porque existem lacunas na lei que asseguram uma certa obscuridade a processos decisórios das instituições ou cargos não eleitos diretamente ou indicados, e garantem uma grande latitude de arbitrariedade das decisões. 
Assim, uma decisão do Conselho dos Guardiões como a proibição de membros do parlamento de concorrer nas últimas eleições não precisa (e talvez não possa) ser explicitada. A islamicidade de todas as leis é determinada por uma maioria dos 6 membro religiosos do Conselho, e a constitucionalidade, por uma maioria de $3 / 4$ de todos os 12 membros. Não existe qualquer consenso, entretanto, sobre como determinar a "islamicidade" de um candidato. Resulta que todas as eleições são supervisionadas indiretamente pelo Guia, já que este indica os membros religiosos do Conselho dos Guardiões. Todos os membros da Comissão da Determinação do Interesse também são indicados pelo guia. Assim, muito embora numa situação fictícia possamos imaginar esses membros religiosos do conselho dos guardiões agindo somente dentro da perspectiva da compatibilidade entre as leis parlamentares e a sharia, a própria natureza fragmentada e não centralizada do corpus jurídico islâmico e da autoridade religiosa (a presença de várias autoridades com opiniões divergentes) conspira para tornar esse corpo legislativo um apêndice parcialmente autônomo do escritório do guia. Os interesses em jogo entre o guia e o conselho são, entretanto, impossíveis de ser sondados.

Apesar de esse sistema fechado reciclar os próprios ocupantes, advindos de grupos de interesse ou coalizões políticas fluidas - é necessário sublinhar, de dentro da elite -, a harmonia institucional é perturbada por tensões surgidas da sociedade. De fato, a sociedade iraniana não interiorizou a fidelidade ideológica ao regime a ponto de haver um processo de formação e reciclagem dos quadros das elites governantes. As elites alternam os quadros do alto escalão, mas a elite não muda substantivamente. Há uma cisão profunda entre a representação que a sociedade como um todo faz da política, e a representação que a elite e os grupos clientes do sistema fazem da política. Os segundos são os insiders (khodi). Os outros são os outsiders (na-khodi). Uma outra forma de representar essa divisão é através do público e do privado (dos quais cada um desses grupos tem uma imagem divergente).

O momento mais recente em que podemos perceber uma "pausa" na desconfiança da sociedade iraniana em relação ao estado e um impulso genuíno de mudança do sistema político através da participação popular foi no começo da revolução islâmica, mas antes da promulgação da constituição e da repressão das dissidências pelo grupo que tomou as rédeas do poder, centrado em Khomeini. Durante a primeira fase da revolução, aconteceu uma reversão do imaginário político tradicional iraniano. Ao invés do distanciamento da política, agora é moralmente recomendável participação; ao invés da sujeição do indivíduo à comunidade e à família, ele se autonomiza; a justiça não é mais vista como resultado da ordem cósmica sustentada pela ação generosa do governante, mas sim como resultado da ação popular.

Mas logo a participação política deixou de ser um mecanismo de autonomização do indivíduo, para se tornar um veículo de uma individualização "pela metade", com um indivíduo autônomo em relação à família mas não em relação ao estado: a realização individual só tem saída ou na participação na repressão, ou no ápice na autoimolação como mártir na guerra contra o Iraque, ambos os trabalhos realizados em parte por voluntários (bassidj). 0 indivíduo deve ser um homo politicus por obrigação. De moralmente evitável, porque especialmente suscetível de corromper moralmente, ou porque está além da moral da comunidade, a ação política passa a ser recomendável, para depois encontrar-se reino do quase obrigatório, a participação como um suporte da, e um apoio à, ideologia do regime. Temos então três momentos do período revolucionário na relação estado-sociedade: 
1. a sociedade se engaja na participação política, identificando-se com o estado que procura construir;

2. o estado se apropria da participação política contra a comunidade, continuando o processo de rompimento com as estruturas sociais comunitárias (modernização), ao separar indivíduo e comunidade;

3. a comunidade volta a se separar (ideologicamente) do estado, voltando-se para dentro de si mesma, e erigindo novos marcos de identidade na linguagem e na ação para reverter o processo de identificação anterior com o estado.

No entanto, essa tentativa de voltar às normas comunitárias e dissociar-se do estado cria por um lado o fenômeno do neo-comunitarismo (o recurso ao policiamento dos costumes como um método de substituição à ação política), e, por outro lado, a criação de um mundo privado paralelo ao mundo público.

No seu artigo "An Introduction to the Public and Private Debate in the Islamic Culture", o teólogo iraniano Mohsen Kadivar afirma que, apesar do fato de que a distinção entre o público e o que é privado ser clara na ética, no direito e na jurisprudência islâmicos, ela não se desenvolveu como um campo de estudo especial. Ele nota que mesmo os termos "público" e "privado" não são encontrados na doutrina islâmica. No entanto, se tivermos em mente duas definições de espaço privado - de acordo com as quais o que é privado é o que deve ser "escondido ou protegido dos outros", ou "aquilo sobre o que o indivíduo exerce soberania ou controle" -, o islamismo reconhece o espaço privado, embora ainda tenhamos que discutir mais pormenorizadamente os seus limites.

Um ponto importante é a questão da fé. Segundo Kadivar, o crente orienta toda a sua vida, seja privada ou pública, segundo os preceitos religiosos. Não há diferença entre as duas esferas. Em outras palavras, a crença religiosa transcende as barreiras entre o público e o privado. De certo modo, a relação do crente com Deus é individual e privada: o seu pecado (quer dizer, a transgressão das ordens de Deus, a prevaricação) recai sobre ele próprio, e o arrependimento (ou então a punição) deve ser somente em relação a Deus - a não ser que seus efeitos se dêem sobre um outro indivíduo, quer dizer, a não ser que se faça mal a outrem ou que se lhe incite a pecar, caso em que o pecado se torna público, o que exige uma punição pública.

Mas como regular a esfera pública? De acordo com Kadivar, um dos principais aspectos de um fato ou coisa pública é, por definição, a sua acessibilidade ao conhecimento de toda a população. Essa esfera pública também tem suas próprias regras religiosas. $O$ crente também está ligado aos outros crentes, e a crença tem uma existência pública autônoma de cada crente individual. Em outras palavras, a crença é uma essência imaterial: a ummah. A comunidade dos crentes é definida pela crença, e não pelas pessoas que crêem; uma sociedade islâmica é definida pelo grau de compatibilidade das ações dos seus membros nominalmente muçulmanos com o corpo de práticas do islã. De forma que uma sociedade islâmica, no limite, é aquela em que não há pecado em público, aquela em que as leis de Deus são cumpridas em público. 
Os crentes são forçados a manter a aparência da permanência de sua identidade em público, mesmo que não o façam para si mesmos. Isso leva a situações que poderiam ser interpretadas como pura hipocrisia ou uma racionalidade individualista das mais maquiavélicas por um observador de fora.

A fé (iman) é um valor; a devoção subjetiva (baten) também é um valor; a salvação depende desses dois fatores, mas a prática de um membro da sociedade influi na fé e na devoção de outros membros. A harmonia pública deve ser um ideal. A prática generalizada, mesmo se ela não reforça sempre e para todo mundo a fé, pelo menos não abala a profunda fé do crente verdadeiro. Em outras palavras, a crença coletiva é obrigatória para o muçulmano, mesmo que ele não tenha um pingo de fé. Isso vale tanto para as regras religiosas quanto para as regras da política.

O público é, em primeiro lugar, o coletivo, e não a realização de desígnios individuais. O coletivo não é representado como um feixe de forças atomizadas (os indivíduos) contidas e controladas por meio de um conjunto de regras idealmente públicas (as leis). A representação da sociedade islâmica é um conjunto de famílias, e não um conjunto de indivíduos isolados. Os limites entre o público e o privado também têm a ver, então, com a diferença entre o coletivo e o individual-familiar, quer dizer, com a definição dos grupos sociais que, no limite, chega à distinção entre muçulmano e infiel. O que é interno ao grupo ou escondido da vista dos outros é privado; a honra está relacionada também à apresentação aos outros de uma aparência de harmonia interna. Os problemas, os conflitos, as dificuldades para se manter unido o grupo, devem ser retirados da esfera pública. A esfera pública, nesse sentido, é o espaço de representação da harmonia social, a publicidade é a imagem corporativa da sociedade - para ela mesma, para seus diferentes grupos, e para o exterior. O que se teme mais é o escândalo - a publicização da discórdia, da desarmonia que deveria ser ocultada e resolvida secretamente. Entre os grupos da sociedade (constituída nuclearmente na família, e não no indivíduo) e, num nível mais abrangente, entre um nacional e um estrangeiro, o que vigora é o chamado ta'arof, quer dizer, a deferência, a concórdia, o bom tratamento de um indivíduo com o seu diferente, com o que é de fora - na-khodi, na-mahram. Ta'arof implica acolhimento, mas não implica intimidade. Não há ta'arof internamente ao grupo. $O$ "outro" se sente bem, mas não deixa de se sentir diferente. Um na-mahram não tem direito de dar palpites na vida interna da família; o que não é um dos nossos (na-khodi), pelo simples fato de ser diferente, não sabe o que é melhor para nós. Tratar o outro com deferência é um modo de manter uma relação estreita com o outro, como uma relação comercial ou uma relação de amizade, mas é, ao mesmo tempo, uma forma de manter um certo afastamento e, principalmente, independência.

Mas há sempre um jogo entre essas noções, e quem é khodi, do grupo, estabelecido, não está tão claro a partir do momento em que se tem como base um estado-nação moderno. Um desses exemplos pode ser notado na ação dos deputados em relação à investigação parlamentar durante o governo Khatami sobre as fundações, em que o espírito corporativo da classe política e do regime prevaleceu sobre o interesse público em racionalizar as práticas econômicas de fundações em termos de impostos, por exemplo, e em termos de relação de sua administração com o estado. Embora tenha havido um inquérito na tentativa de reformar essas instituições, prevaleceram as regras de conduta pública, em que não se pode ofender o outro, rebaixá-lo, para manter a "paz social". O deputado conservador Javad Larijani explicou porque o processo não foi público: 
“Há uma realidade escondida, uma hipocrisia que mantém a paz. Ela protege a dignidade do outro (...) Se você não falar tudo abertamente, é melhor. Ser capaz de manter segredo mesmo se você tiver que enganar é considerado um sinal de maturidade (...) Não temos quer ser pessoas ideais. Todo mundo mente. Vamos ser bons mentirosos" (Sciolino 2002:35).

A noção de insider (khodi) na política iraniana também está ligada fundamentalmente à ideologia revolucionária, e mais propriamente à herança de Khomeini. Todos aqueles que querem participar do poder, que almejam ter alguma legitimidade e possibilidade de agir na política, de se inserirem como atores no sistema político se candidatando ou participando no espaço público, invocam a herança de Khomeini, a perpetuação dos ideais da revolução, mesmo, e principalmente, aqueles (insiders) que sustentam que, para o sistema ser preservado, ele deve ser reformado. Em outras palavras: mesmo os reformistas são insiders, e lutam contra todos aqueles que contestam essa divisão do poder político e esse modo de agir na política baseado na privatização do processo político e na coerção empregada no espaço público.

Enquanto essas duas esferas forem autônomas (o estado e seus agentes - o hezbollah, as fundações, os bassidj, a polícia etc. - dominando a esfera pública, e a vida privada relativamente segura) a paz civil não é seriamente abalada: as autoridades são coniventes ou corruptíveis, assegurando uma certa liberdade no domínio privado; e a repressão procura assegurar os interesses da classe governante criando medo na população e impossibilitando-a de assumir um papel mais afirmativo no espaço público. O grande problema surge quando ocorre um acontecimento que mude a configuração de poder e possibilite a entrada de outsiders no processo político, e foi exatamente isso que ocorreu com a eleição de Mohammad Khatami.

No fundo, o projeto de governo de Khatami, que se convencionou chamar de "reformismo", baseia-se numa vontade de renovar os quadros governantes através da inclusão criteriosa de pessoas que até então estavam de fora da política. Isso quer dizer abrir o campo do diálogo político, o que foi feito autorizando a publicação de jornais e revistas (o ministro do interior de Khatami) e engajando o governo num diálogo mais direto com a sociedade, mas também tinha um aspecto mais funcional: Khatami procura aumentar o nível de apoio ao regime ao salientar o aspecto da participação popular no seu governo, seja através das eleições, seja através de uma resposta da opinião pública às suas políticas.

Mas, apesar disso, não se pode dizer que ele procurava renovar a elite governante de fora para dentro, isto é, formando e trazendo novos membros à elite, fazendo outsiders tornarem-se insiders. Há uma "vontade de absorver e adaptar" nascida de uma própria crise do regime. Há uma espécie de barganha com a sociedade civil. Os reformistas procuram estender o círculo dos insiders (os participantes integrais no processo político), acomodar demandas "legítimas" (segundo eles) da população, melhorar o governo do país, aumentar acesso a cargos públicos (dominado por relações clientelistas). Em troca, querem uma aceitação dos princípios do regime. O problema do programa de Khatami é que essa abertura da participação política integral só é possível com a extensão do Estado de direito e o fortalecimento da sociedade civil, mas estes só são possíveis com uma mudança do sistema (Boroumand \& Boroumand 2000). Mas acontece que o sistema não pode ser modificado. 
Encontramo-nos diante de três grandes tendências do pensamento político da elite iraniana, e nenhuma das três contesta a estrutura política do regime, mas sim o seu funcionamento.

Segundo uns, (a) uma vez que o sistema é is/âmico, a situação só pode ser boa (e quem critica a situação é contra o islã), e, segundo outros, (b) uma vez que o sistema é is/âmico, a situação só não é perfeita devido à ação de elementos não is/âmicos internos e externos. Uma terceira vertente que pode ser identificada é a reformista, que afirma que o sistema é bom, mas as pessoas que fazem que ele funcione, não. (c) O sistema é ótimo, mas só não é perfeito porque há alguns homens nele que não são perfeitos.

Essas tendências são tipos ideais, e não uma descrição empírica da realidade, e quase sempre se aplicam a uma parcela da realidade social julgada num determinado momento, e não ao regime tomado em sua totalidade. Mas o que devemos sublinhar aqui é o fato de que a regra fundamental do jogo político da república islâmica é que, mesmo a situação não sendo boa, não foram os princípios do sistema que geraram a situação.

Segundo os partidários de um ponto de vista que podemos chamar de "revolucionário", que tem em vista o paradigma de ação política surgido da revolução e mantém o regime como um ideal utópico, a utopia do estado perfeito realizar-se-á quando a sociedade for expurgada de todos os seus elementos impuros.

Segundo o campo reformista, o sistema poderia ser otimizado se esses homens imperfeitos se esforçassem para agir segundo as normas do sistema, que são por definição boas. Essa noção reformista de que as regras são boas mas o cumprimento da lei deixa a desejar leva diretamente à questão de como fazer cumprir a lei. Aí o campo reformista encontra-se no impasse de como lidar a) com a área cinzenta entre a legalidade e a ilegalidade em que se baseiam as redes pessoais da política iraniana e o processo de tomada de decisões; b) com as ações claramente ilegais de "agentes por delegação" que fazem o trabalho sujo de certas instâncias do alto escalão jurídico, religioso e burocrático.

É interessante notar uma certa volta à concepção tradicional de poder, embora, naturalmente, em outros termos. Encontramos aí uma representação do poder análoga à representação tradicional, e em oposição à posição unanimista/utópica da revolução, representada segundo as duas correntes (a) e (b). Segundo a concepção tradicional, num segundo momento, o monarca é bom, mas a corte é ruim. Esse segundo momento, que é um momento estável e o mais freqüente (já que raramente a situação é ótima), passa, durante a década de 80, a representar a gestão ruim dos seguidores de Khomeini, mas sem responsabilizar o Imam. Assim, de um modo semelhante, a figura carismática de Khomeini, distanciado, neutro, sua aura mística planando acima das contendas das facções do regime, é substituída pela figura do próprio regime, que é fortalecido institucionalmente pouco antes da morte do Imam. Se, durante o período revolucionário, era o carisma de Khomeini que sustentava o velayate faqih, no período pós-revolucionário, é através da instituição do velayate motlaqaye faqih que se procura perenizar efeitos estabilizantes do carisma (já que institucionalizar o carisma seria impossível). Mas essa tentativa de perenizar a estabilidade é de saída um fracasso, porque a continuação da ordem revolucionária original (o Guia e sua entourage são bons) é impossível. A visão que prevalece na maioria da população é um retorno à representação tradicional do poder, tanto em sua vertente normativa (o distanciamento da política), quanto em sua vertente cognitiva: chega-se ao 
ponto em que tanto o Guia quanto seus seguidores são maus. Mas a elite se encontra ainda em um outro momento: para ela, o Guia, que hoje, desprovido de carisma, é a personificação do sistema, é bom por causa disso. Nem se cogita levantar a questão de sua responsabilidade porque sua falibilidade está simplesmente fora do horizonte de pensamento da elite, já que assumir a falibilidade do Guia seria assumir a imperfeição do sistema, e indiretamente a sua própria incapacidade de governar. De fato, a legitimação da parte do clero que participa da política advém da sua presunção de moralidade acima das pessoas comuns. Mas, por outro lado, se o Guia/sistema é bom, o funcionamento claudicante das instituições estatais só pode ser atribuído a elementos defeituosos agindo dentro do sistema - seja ele a imperfeição externa (para o pensamento revolucionário), seja a imperfeição "natural", humana, interna (para o pensamento reformista).

Assim, é mais fácil perceber o que está em jogo nos episódios de repressão e liberalização da imprensa e, de forma mais contundente, nos protestos de 1999 e 2003.

A contestação pública surge e ganha força impulsionada por eventos específicos:

1. a chegada de Khatami ao poder com seu discurso de estado de direito, defesa da constituição, promoção da sociedade civil, participação dos jovens;

2. uma abertura num primeiro momento, principalmente nos dois primeiros anos de governo de Khatami, com permissões de publicação de jornais e ampliação do espaço de discussão política. Essa abertura propiciou, no entanto, os primeiros confrontos entre estudantes que apoiavam o presidente Khatami e militantes (bassidj) na universidade, já que logo após a vitória de Khatami foram criadas unidades de controle ideológico (bassidj) em cada universidade, para conter o ativismo político estudantil;

3. a imprensa publica reportagens acusando a participação do Ministério da Inteligência numa série de assassinatos políticos;

4. os estudantes, que já haviam estado a protestar sobre as condições das universidades, saem a protestar também sobre os assassinatos.

5. a repressão aos protestos por membros das milícias islâmicas (ansare hezbollah) e pela polícia leva a protestos contra o governo (responsável pela polícia) e, quebrando um tabu, também ao Guia (tido como responsável direto pelas milícias).

Foram esses eventos que possibilitaram a criação de um discurso público e expresso através de um movimento de contestação que deslegitimava sistematicamente todo o sistema islâmico, e isso se deu através da linguagem do estado de direito e da responsabilidade, segundo as evidências que percebemos nos diagnósticos da situação apresentados pelos estudantes. Em suma, a) as autoridades desrespeitam a lei e/ou são coniventes com esse desrespeito; b) o presidente não tem poderes para fazer respeitar a lei, e é também em certa medida culpado pela situação. ${ }^{6}$ 
Como reflexo à dicotomia entre khodi e na-khodi, as críticas ao funcionamento do sistema político são geralmente críticas pessoais aos altos escalões do governo - ao chefe do judiciário, ao Conselho dos Guardiões (aiatolá Jannati), ao presidente e ao Guia, e são facilmente traduzíveis (em primeiro lugar pela classe dirigente nas suas reações) como críticas ao sistema em si. Nas manifestações de 1999, algumas das palavras de ordem entoadas pelos estudantes eram: "Os clérigos vivem como reis, enquanto o povo empobrece!"; "Khatami, Khatami, mostrenos o seu poder ou renuncie!"; "Khamenei, tenha vergonha, renuncie à liderança!"; "Khamenei, tenha vergonha, e deixe o povo em paz!" ; "Os Ansar cometem crimes, e o Guia os protege!".

Nos protestos de 2003, o tom parece ter aumentado. Os estudantes gritavam: "Khatami! Khatami! Renuncie! Renuncie!"; “Morte a Khamenei!" e "Morte a Rafsandjani!", e "Fora com a República Islâmica! O regime clerical aproxima-se do seu fim! Ó ditadura islâmica, o aniversário dos ataques aos dormitórios [julho de 1999] se aproxima!". Ao estender-se a outras áreas da capital, gritos de "Renúncia" e "Referendo" eram escutados tanto em Tehran Pars, um bairro de classe trabalhadora no leste da capital, quanto em Karaj, um bairro de classe média no oeste. Ao serem divulgadas notícias e imagens dos protestos em Teerã, também ocorreram confrontos em cidades como Tabriz, Shiraz, Esfahan, Ahvaz e Mashhad. "Povo, o que estão esperando? O Irã agora é a Palestina!"; "Morte ao ditador e à ditadura!"; "Canhões, tanques e mísseis - os akhund [religiosos] devem morrer!” ; “Morte ao Xá... Akbar Xá!" [uma alusão a Ali Akbar Rafsandjani]; "Morte a Hashemi Araqi!" [Ayatollah Hashemi Shahrudi, chefe do judiciário, que é iraquiano (araqi)]. Ao contrário de 1999, a polícia não interveio em 2003, e uma testemunha disse que "mesmo alguns dos Pasdaran (...) perseguiram os marginais e simpatizaram com os estudantes". ${ }^{8}$

\section{CONCLUSÃO}

Ao trazer o debate político para uma contestação pública, as manifestações estudantis de 1999 e de 2003 deram mais visibilidade à dimensão da oposição ao regime clerical iraniano. A outra face dessa publicização foi a exigência de que a ação política seja guiada por normas públicas claras, e que a lei seja válida para todos. Houve denúncias de apropriação de bens públicos (chamando Rafsandjani de Xá), de enriquecimento ilícito dos religiosos (os mulás andam de Mercedes enquanto o povo morre de fome), e finalmente apelos abertos à sedição (comparando o Irã à Palestina, conclamando - metaforicamente? - à morte dos clérigos). Num momento, um grupo de pessoas passou com uma bandeira iraniana sem a insígnia de Allah em forma de espada característica no meio.

Finalmente, há evidências de que esse sentimento de alienação em relação ao estado não desapareceu, mas apenas submergiu após a repressão. Uma alienação que, durante um momento, no primeiro governo de Khatami, tendeu a se mostrar sobretudo social, mostra-se no final do seu segundo mandato como também política. A desilusão com o governo Khatami levou a uma abstenção maciça nas últimas eleições parlamentares de 2004 (que chegou a $80 \%$ em alguns locais), depois que o Conselho dos Guardiões proibiu a candidatura de cerca de três mil pessoas, dentre as quais oitenta parlamentares reformistas, e também nas últimas eleições presidenciais 
(60\%). A população volta a se fechar em si mesma, procurando realizar-se mais na vida econômica do que na vida política, e mantendo uma vida social dupla - uma, pública, outra, privada - e o protesto e a contestação voltam a existir somente veladamente, na esfera privada, através de pequenas ações que trazem um alívio momentâneo, mas que não ocasionam uma ação coletiva de protesto que possa vir a ter um reflexo político, justamente por sua característica pulverizada e pontual, quase que individual.

No entanto, pode-se notar a permanência das mudanças em relação ao modo de se fazer política no Irã introduzidas com a eleição de Khatami. As eleições se tornaram mais um espetáculo de imagens, com quantias vultosas gastas em propagandas de todo tipo (notadamente com a participação de jovens nas campanhas). Além disso, os conservadores também mudaram o foco de sua propaganda política, deixando de lado exortações à dor e ao martírio e à revolução, e utilizando cada vez mais slogans como o das eleições de 2004: “Um Irã livre, desenvolvido e alegre" (Iran-e azad, abad, va shad). Os conservadores falavam de bem-estar econômico e em transformar o país num "Japão islâmico" - uma política de conservadorismo cultural e político e abertura econômica que se explica pelos seus laços com os grandes comerciantes (o bazar) - e uma nova geração de conservadores tenta conciliar essa plataforma de desenvolvimento (liberalização) econômico com algum respeito à autonomia individual (quer dizer, à vida privada). Resta ver o que nos reserva a relação entre esses "novos conservadores" mais pragmáticos e a "velha guarda" da revolução, agora representada pelo próprio presidente Ahmedinejad. 


\section{NOTAS}

1 Altas autoridades religiosas criticam freqüentemente o Estado por tentar organizar, centralizar e homogeneizar o discurso religioso.

2 Outra categoria central, e talvez mais controversa do que o binômio público-privado (mas paralela a ela), é a de "sociedade civil", mas sua análise exigiria por si só que lidasse com essa questão especificamente.

3 Em outras palavras, o estado, por ser islâmico, pode valer-se do interesse a longo prazo para fazer valer uma regra de exceção (a lei e o interesse do estado mandam não cumprir uma lei islâmica...). Temos aí a religiosificação da ordem estatal, e não uma simples expressão de uma natureza político-religiosa.

4 A Comissão tinha como presidente o presidente da Assembléia dos Expertos e como vice-presidentes Khamenei e Rafsandjani, e era composta de 18 clérigos e 2 laicos, com cinco membros do Majlis (Parlamento).

5 Devemos também reparar no fato de que, embora Khamenei tenha sido eleito Guia em 4 de junho de 1989, um dia após a morte de Khomeini, as emendas constitucionais só foram votadas em referendo em 8 de julho, juntamente com as eleições presidenciais, 0 que resulta num ato inconstitucional por parte da Assembléia dos Expertos, que elegeu Khamenei.

6 Logo antes das últimas eleições presidenciais, os estudantes gritam num debate com o então presidente, na Universidade de Teerã: "Khatami, você virou as costas para nós".

7 Segundo uma testemunha ocular anônima, em <http://www.iranian.com/Opinion/2000/July/Students/index.html>.

8 http://www.iran-press-service.com/articles_2003/Jun-2003/student _ unrest_12603.htm. 


\section{REFERÊNCIAS BIBLIOGRÁFICAS}

ABDO, Geneive. 2001. "Iran's Generation of Outsiders". The Washington Quarterly 24(4):163-171.

ABDO, Geneive \& Jonathan Lyons. 2003. Answering only to God: Faith and Freedom in Twenty-First-Century Iran. New York: Henry Holt.

ABRAHAMIAN, Ervan. 199? Khomeinism - Essays on the Islamic Republic. Berkeley: University of California Press. http://ark.cdlib.org/ark:/13030/ft6c6006wp

ADELKHAH, Fariba; Jean-François Bayart; Olivier Roy. 1993. Thermidor en Iran. Paris: Complexe.

ADELKHAH, Fariba. 1997. "Iran: vers un espace public confessionnel?" Les Études du CERI no 27. http://www.ceri-sciencespo.com/publica/etude/etude27.pdf

. 1998. Etre moderne en Iran. Paris: Karthala.

APPLEBY, R. Scott \& Martin E. Marty (eds.). 1993. Fundamentalisms and the State. Chicago: University of Chicago Press.

ARJOMAND, Said Amir. 1993. "Shi'ite Jurisprudence and Constitution Making in the Islamic Republic of Iran". In R. Scott Appleby \& Martin E. Marty (eds.) Fundamentalisms and the State. Chicago: University of Chicago Press.

. 2000. "Civil Society and the Rule of Law in the Constitutional Politics of Iran under Khatami". Social Research 67(2): $283-301$.

. 2002. "The Reform Movement and the Debate on Modernity and Tradition in Contemporary Iran". International Journal of Middle Eastern Studies 34: 719-731.

BOROUMAND, Ladan \& Roya Boroumand. 2000. "Illusion and Reality of Civil Society in Iran: an ideological debate". Social Research 67(2): 303-344.

BUTEL, Eric. "L'Individu Postislamiste en Iran: la nouvelle jeunesse". Cahiers d'Études sur la Méditerranée Orientale et le Monde Turco-iranien 26. http://cemoti.revues.org/document37.html

DIGARD, J.P.; Bernard Hourcade; Yann Richard. 1996. L'Iran au XXème Siècle. Paris: Fayard.

DJALILI, Mohamed-Reza. 2001. Iran, I'lllusion Réformiste. Paris: Presses de Sciences-Po.

FISCHER, Michael. 1980. Iran: From Religious Dispute to Revolution. Cambridge, MA: s/e.

HOURCADE, Bernard. 2000. Iran: Nouvelles Identités d'une République. Paris: Éditions Belin.

. 2004. "Iran: a Spring of Change". Le Monde Diplomatique 2.

KADIVAR, Mohsen. 2002. "Velayat-e Faqih and Democracy". Paper presented to the Middle East Studies Association of North America Conference. Washington, November 24, 2002.

Disponível em: www.kadivar.com/htm/english/papers/Velayat-e\%20Faghigh.htm

2003. "An Introduction to the Public and Private Debate in Islamic Culture". Social Research 70(3): 659-680. Disponível em: http://www.kadivar.com (persa) e http://www.kadivar.com/index.asp (inglês).

KAMRAVA, Mehran. 2001. “The Civil Society Discourse in Iran”. British Journal of Middle Eastern Studies 28(2): 165-185. 
KHOSROKHAVAR, Farhad. 1993. L'Utopie Sacrifiée: Sociologie de la Révolution Iranienne. Paris: Presses de la Fondation Nationale des Sciences Politiques. 1997. Anthropologie de la Révolution Iranienne. Paris: L'Harmattan.

. 2000. “Toward an Anthropology of Democratization in Iran". Critique: Critical Middle Eastern Studies 16: 3-29.

KHOSROKHAVAR, Farhad \& Olivier Roy. 1999. Iran, Comment Sortir d'une Révolution Religieuse. Paris: Seuil.

KIAN-THIÉBAUT, Azadeh. "L'Individu dans le Monde: paradoxe de l'Iran islamique". Cahiers d'Études sur la Méditerranée Orientale et le Monde Turco-iranien 26. http://cemoti.revues.org/document31.html . 2005. La République Islamique d'Iran: de la maison du Guide à la raison d'État. Paris: Éditions Michalon.

MAHDI, Ali Akbar. 1999. “The Student Protests of July". Journal of Iranian Research and Analysis 15:5-32. Disponível em: http://www.iranian.com/Opinion/2000/July/Students/index2.html

MINOUI, Delphine (ed.). 2001. Jeunesse d'Iran: Les voix du changement. Paris : Autrement.

NONNEMAN, Gerd. 2001. "Rentiers and Autocrats, Monarchs and Democrats, State and Society: the Middle East between globalization, human agency, and Europe". International Affairs 77(1): 141-162.

SCIOLINO, Elaine. 2001. Persian Mirrors: the elusive face of Iran. New York: Simon \& Schuster. 


\section{Dissensões sobre o Público e o Privado na República Islâmica do Irã}

\section{RESUMO}

Durante os dois mandatos de Mohammad Khatami como presidente do Irã (1997-2001; 2001-2005), observouse um debate intenso na sociedade iraniana a respeito da concepção do espaço político e dos fundamentos da ação política. Uma parte essencial desse debate foi a participação dos estudantes. Mas essa política de reforma teve o resultado inesperado de trazer à tona as vozes de contestação da organização normativa autoritária do espaço público, expondo as contradições constitutivas do sistema e seu funcionamento ambíguo, e ameaçando por um momento a dominação da elite política religiosa-revolucionária. Podemos perceber nos protestos dos estudantes em 1999 e 2003 uma vontade de reformulação simbólico-institucional da divisão público-privado que tem regido as relações entre o estado e a sociedade do Irã desde o estabelecimento da República Islâmica. PALAVRAS-CHAVE: Irã, islamismo, estudantes, público-privado.

\section{Dissent over Public and Private Spheres in Iran}

\section{ABSTRACT}

Throughout Mohammad Khatami's two presidential periods (1997-2001; 2001-2005), Iranian society experienced a powerful debate on the concepts of political space and the foundations of political action. An essential element in this debate was the students' participation. Yet Khatami's policy had the unexpected effect of bringing into the open the dissenting voices against the normative and authoritarian framing of the public space. As a result, Iranian society was exposed to the inherent contradictions of the system and its hazy functioning, jeopardizing for a moment the ascendancy of the religious revolutionary elites. In the protests of 1999 and 2003 it has been noticed a drive to reformulate, symbolically and institutionally, the boundaries between the public and private spheres that have ruled Iranian State-Society relations since 1979. KEY WORDS: Iran, Islamism, students, public/private. 